\title{
Cationic Pd(IV)-Induced Highly Diastereoselective Arylative Cascade Cyclization of Allene-Tethered Cyclohexadienones Leading to Oxygenated Bicyclic Motifs
}

Gullapalli Kumaraswamy *a,b, i Maram Gangadhar ${ }^{\text {a }}$ Vankudoth Ramesh ${ }^{\mathrm{a}}$ Kukkadapu Ankamma $^{\mathrm{a}}$ and Balasubramanian Sridhar ${ }^{\S}$

Organic Synthesis and Process Chemistry Division

CSIR-Indian Institute of Chemical Technology, Hyderabad-500 007, Telangana, India.

E-mail: gkswamy iict@yahoo.co.in

Tel: +91-40-27191614, Fax: +91-40-27193275 


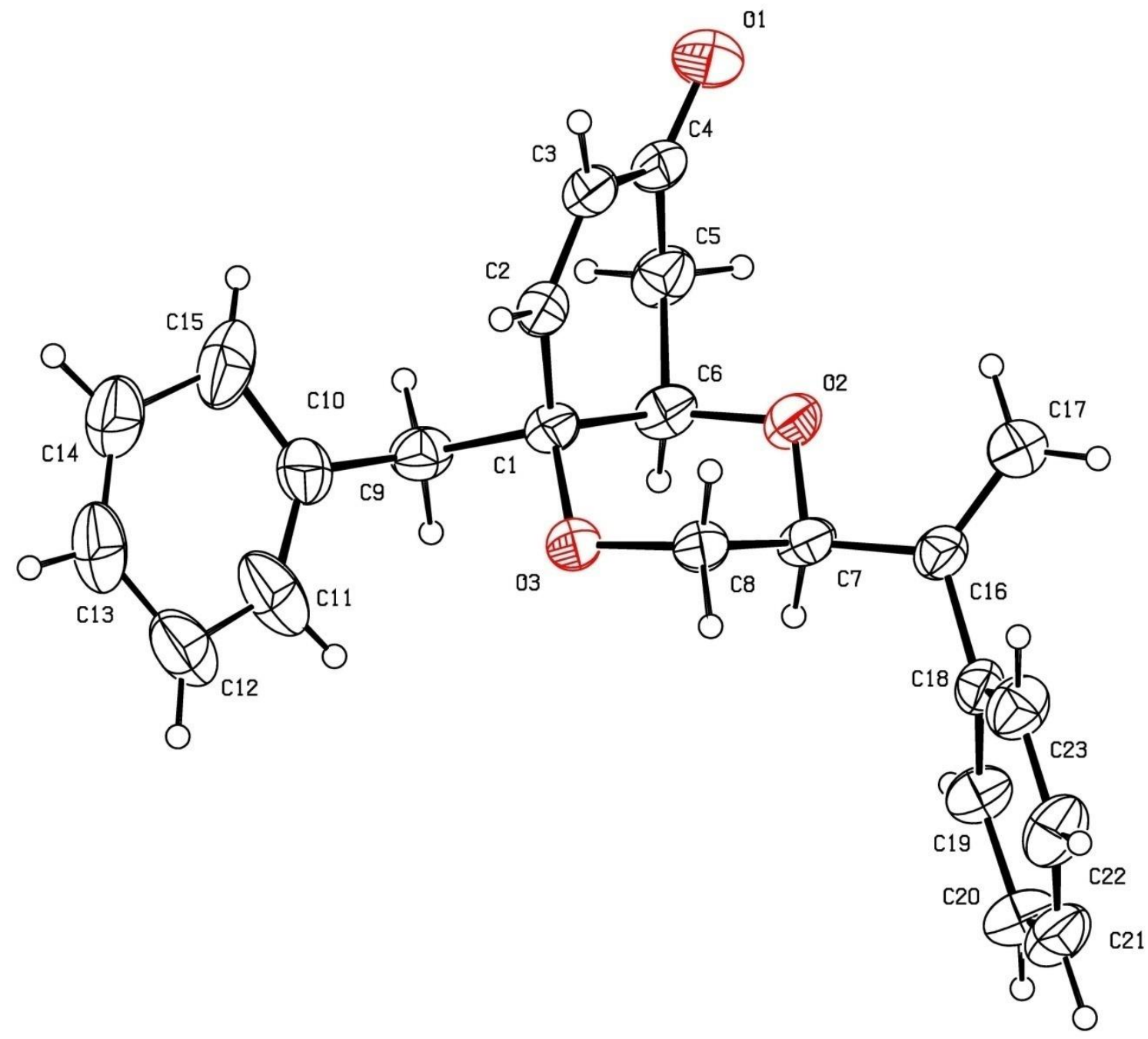

Crystal structure of $4 \mathbf{u}$ (CCDC reference number 1921130) 


\section{checkCIF/PLATON report}

Structure factors have been supplied for datablock(s) BG6lm

THIS REPORT IS FOR GUIDANCE ONLY. IF USED AS PART OF A REVIEW PROCEDURE FOR PUBLICATION, IT SHOULD NOT REPLACE THE EXPERTISE OF AN EXPERIENCED CRYSTALLOGRAPHIC REFEREE.

No syntax errors found. CIF dictionary Interpreting this report

\section{Datablock: BG6lm}

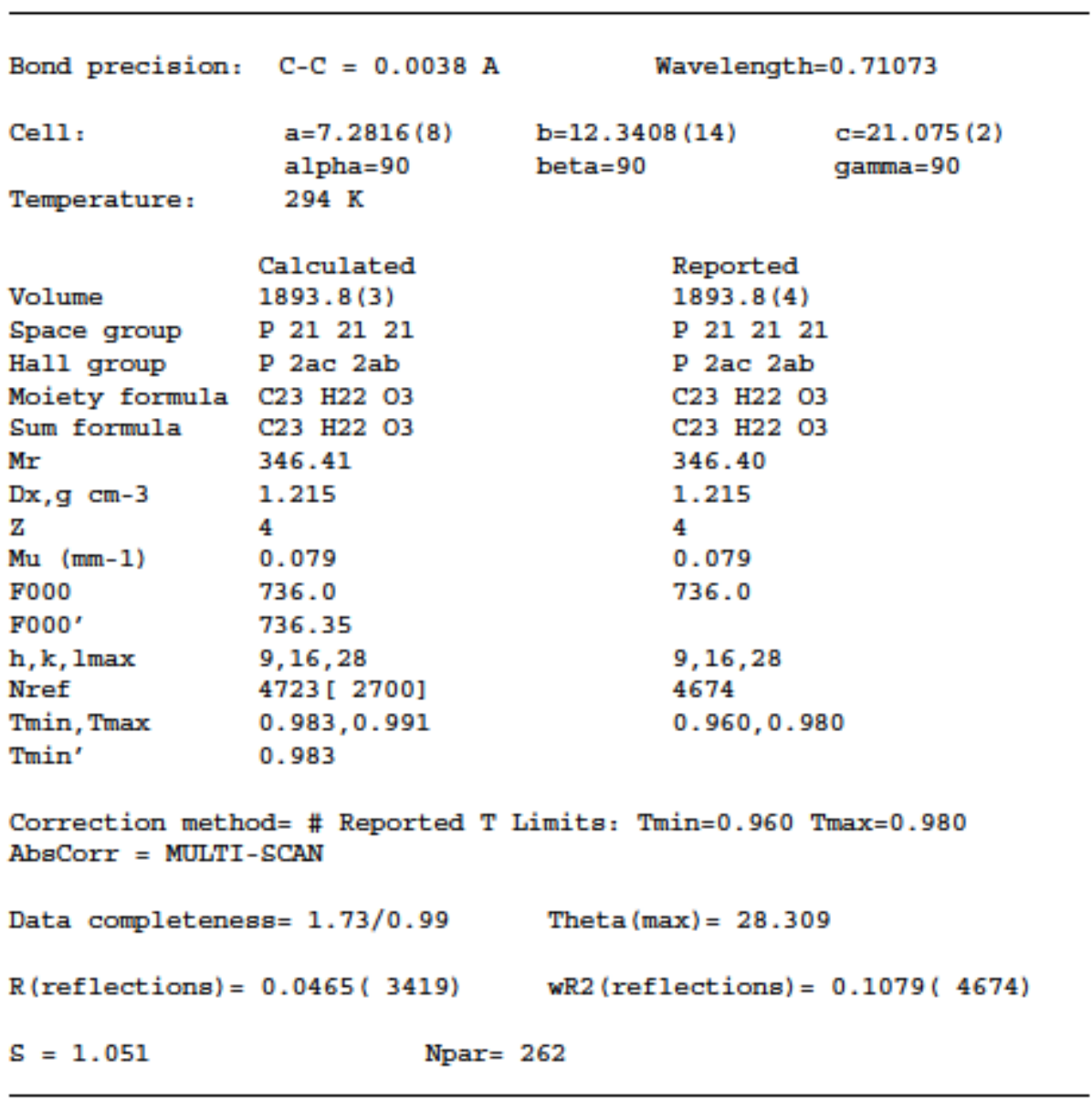

The following ALERTS were generated. Bach ALERT has the format teat-name_ALRRT_alert-type_alert-level.

Click on the hyperlinka for more detaila of the teat. 
X-ray Crystallography.

$\mathrm{X}$-ray data for the compounds were collected at room temperature using a Bruker Smart Apex CCD diffractometer with graphite monochromated MoK $\alpha$ radiation $(\lambda=0.71073 \AA)$ with $\omega$-scan method [1]. Preliminary lattice parameters and orientation matrices were obtained from four sets of frames.

Integration and scaling of intensity data were accomplished using SAINT program [1]. The structure was solved by direct methods using SHELXS [2] and refinement was carried out by full-matrix least-squares technique using SHELXL [2]. Anisotropic displacement parameters were included for all non-hydrogen atoms. The atoms $\mathrm{C} 12 / \mathrm{C} 13 / \mathrm{C} 14$ of the phenyl ring was disordered over two sites and their site occupation factors were refined with equal occupancy. DFIX and SIMU constraints were applied to disordered phenyl group. All $\mathrm{H}$ atoms were positioned geometrically and treated as riding on their parent $\mathrm{C}$ atoms $\left[\mathrm{C}-\mathrm{H}=0.93-0.97 \AA\right.$ and $\mathrm{U}_{\mathrm{iso}}(\mathrm{H})=1.5 \mathrm{U}_{\text {eq }}(\mathrm{C})$ for methyl $\mathrm{H}$ or $1.2 \mathrm{U}_{\mathrm{eq}}(\mathrm{c})$ for other $\mathrm{H}$ atoms].

Crystal Data for BG61: $\mathrm{C}_{23} \mathrm{H}_{22} \mathrm{O}_{3}(M=344.41 \mathrm{~g} / \mathrm{mol})$ : orthorhombic, space group $\mathrm{P} 2{ }_{1} 2{ }_{1} 2_{1}$ (no. 19), $a=7.2816(8) \AA, b=12.3408(14) \AA, c=21.075(2) \AA, V=1893.8(4) \AA^{3}$, $Z=4, T=294.15 \mathrm{~K}, \mu($ Mo K $\alpha)=0.079 \mathrm{~mm}^{-1}$, Dcalc $=1.2079 \mathrm{~g} / \mathrm{cm}^{3}, 23672$ reflections measured $\left(3.82^{\circ} \leq 2 \Theta \leq 56.62^{\circ}\right), 4674$ unique $\left(R_{\text {int }}=0.0323, R_{\text {sigma }}=0.0256\right)$ which were used in all calculations. The final $R_{1}$ was $0.0506(\mathrm{I}>2 \sigma(\mathrm{I}))$ and $w R_{2}$ was 0.1147 (all data). CCDC 1921130 contains supplementary Crystallographic data for the structure. These data can be obtained free of charge at www.ccdc.cam.ac.uk/conts/retrieving.html [or from the Cambridge Crystallographic Data Centre (CCDC), 12 Union Road, Cambridge CB2 1EZ, UK; fax: +44(0) 1223336 033; email: deposit@ccdc.cam.ac.uk].

1. Bruker (2001). SAINT (Version 6.28a) \& SMART (Version 5.625). Bruker AXS Inc., Madison, Wisconsin, USA.

2. Sheldrick G. M. (2015) Acta Crystallogr C71: 3-8. 